\title{
Complete response in gallbladder cancer to erlotinib plus gemcitabine does not require mutation of the epidermal growth factor receptor gene: a case report
}

\author{
Kabir Mody ${ }^{1}$ Edward Strauss², Robert Lincer ${ }^{3}$, Richard C Frank ${ }^{1 *}$
}

\begin{abstract}
Background: Gallbladder cancer typically follows an aggressive course, with chemotherapy the standard of care for advanced disease; complete remissions are rarely encountered. The epidermal growth factor receptor (EGFR) is a promising therapeutic target but the activity of single agent oral EGFR tyrosine kinase inhibitors is low. There have been no previous reports of chemotherapy plus an EGFR-tyrosine kinase inhibitor (TKI) to treat gallbladder cancer or correlations of response with the mutation status of the tyrosine kinase domain of the EGFR gene.

Case presentation: A 67 year old man with metastatic gallbladder cancer involving the liver and abdominal lymph nodes was treated with gemcitabine $(1000 \mathrm{mg} / \mathrm{m} 2)$ on day 1 and 8 every 21 days as well as daily erlotinib (100 mg). After four cycles of therapy, the CA 19-9 normalized and a PET/CT showed a complete remission; this response was maintained by the end of 12 cycles of therapy. Gemcitabine was then discontinued and single agent erlotinib was continued as maintenance therapy. The disease remains in good control 18 months after initiation of therapy, including 6 months on maintenance erlotinib. The only grade 3 toxicity was a typical EGFR-related skin rash. Because of the remarkable response to erlotinib plus gemcitabine, we performed tumor genotyping of the EGFR gene for response predicting mutations in exons 18, 19 and 21. This disclosed the wild-type genotype with no mutations found.

Conclusion: This case report demonstrates a patient with stage IV gallbladder cancer who experienced a rarely encountered complete, prolonged response after treatment with an oral EGFR-TKI plus chemotherapy. This response occurred in the absence of an EGFR gene mutation. These observations should inform the design of clinical trials using EGFR-TKls to treat gallbladder and other biliary tract cancers; such trials should not select patients based on EGFR mutation status.
\end{abstract}

\section{Background}

Biliary tract cancers (BTC) include carcinomas of the gallbladder and intra- and extra-hepatic bile ducts (cholangiocarcinomas). Gallbladder cancer is the most common type worldwide, affects women more frequently than men and is considered to be the most aggressive form of BTC with the shortest survival [1]. In contrast to cholangiocarcioma, gallbladder cancer $(\mathrm{GBC})$ has a

\footnotetext{
* Correspondence: richard.frank@norwalkhealth.org

'Department of Medicine, Norwalk Hospital, 34 Maple Street, Norwalk, CT 06856 USA

Full list of author information is available at the end of the article
}

distinct molecular pathogenesis and may require a different therapeutic approach $[1,2]$.

The majority of BTC present at an advanced, incurable stage and are typically treated with chemotherapy drugs such as 5-fluoruracil, gemcitabine and cisplatin, often in combination. Response rates range from approximately $20-40 \%$ and median overall survivals from 8-14 months [1]. The most notable advance in the treatment of BTC is the result of a phase III randomized trial of gemcitabine versus gemcitabine plus cisplatin in which the chemotherapy doublet improved overall survival by 3.6 months [3]. In order for further advances to be made, however, it is likely that a targeted biologic therapy will
C Biomed Central

(c) 2010 Mody et al; licensee BioMed Central Ltd. This is an Open Access article distributed under the terms of the Creative Commons Attribution License (http://creativecommons.org/licenses/by/2.0), which permits unrestricted use, distribution, and reproduction in any medium, provided the original work is properly cited. 
need to be successfully added to chemotherapy, as has become the paradigm in modern oncologic therapy.

The EGFR family is a prominent target of biological therapies against multiple epithelial malignancies. In gastrointestinal carcinomas, monoclonal antibodies targeting EGFR/EGFR-1 (cetuximab, panitumomab) and EGFR-2 (trastuzumab) have become part of the standard treatment armamentaria against colorectal and gastric cancers, respectively $[4,5]$. In pancreatic cancer, the combination of gemcitabine plus the oral EGFR-tyrosine kinase inhibitor (TKI) erlotinib demonstrated a small but statistically significant improvement in overall survival compared with gemcitabine alone [6]. The data in BTC is much more limited: single agent erlotinib resulted in a $17 \%$ progression free survival at 6 months in previously treated patients [7], and both a case report [8] and an ongoing phase II trial [9] support the benefit of adding cetuximab to chemotherapy.

Based on these data and our observation of the activity of erlotinib plus gemcitabine in a patient with refractory gallbladder cancer [10], we utilized this regimen in the front-line setting for the patient herein presented. We also analyzed tumor EGFR DNA for the presence of activating mutations that predict for response to EGFRTKIs [11]. This analysis is the first published report correlating the EGFR tyrosine kinase domain genotype with response to an EGFR-TKI in a patient with BTC.

\section{Case Presentation}

\section{Clinical presentation}

A 67 year old man in good health presented to our emergency department with right upper quadrant pain. He was a former cigarette smoker with a medical history that included hypertension, atrial fibrillation, and coronary artery disease requiring angioplasty eight years before. His medications included dlitiazem, propafenone, coumadin, aspirin, atenolol, atorvastatin and lisinopril. Physical examination was remarkable only for right upper quadrant tenderness. Routine complete blood count and serum chemistry panel were within normal limits. Ultrasound demonstrated mobile densities in the gallbladder and a submucosal mass. An intended laparoscopic cholecystectomy was converted to an open procedure due to dense fibrosis and inflammation of the gallbladder. The gallbladder specimen revealed a moderately differentiated adenocarcinoma involving the full thickness of the gallbladder wall with extension into the serosa and with both perineural and lymphovascular invasion. One month later, after referral to a tertiary cancer center, he underwent a partial hepatectomy with resection of segments 4 and 5, pelvic lymphadenectomy, common bile duct excision, and reconstruction using a Roux-en-Y hepaticojejunostomy. Pathology revealed residual carcinoma involving the gallbladder bed with extension into the hepatic parenchyma; the lymph nodes were uninvolved. No adjuvant therapy was administered. Fourteen months later, computed tomography $(\mathrm{CT})$ of the abdomen showed new hepatic metastases in segments 5 and 8. Positron emission tomography (PET)/CT scan with 18-fluorodeoxyglucose demonstrated the liver lesions to have SUV 6.3, a focus in the portacaval region of SUV 13.6 and a soft tissue mass inferior to the celiac trunk of SUV 6.0. The CA 19-9 was 48 (upper limit of normal $35 \mathrm{IU} / \mathrm{mL}$ ) and CEA normal. He remained well with no complaints of abdominal pain, weight loss, or pruritus and the physical examination at the initiation of chemotherapy was unremarkable.

\section{Treatment and Response}

The patient was treated in a non-protocol fashion with fixed-dose rate gemcitabine $(1000 \mathrm{mg} / \mathrm{m} 2$ administered at $10 \mathrm{mg} / \mathrm{m} 2$ per minute) [12] on day 1 and 8 every 21 days, plus erlotinib $100 \mathrm{mg}$ daily. After four cycles of therapy, a PET/CT scan showed resolution of all FDGavidity and the CA 19-9 declined into the normal range (Figures 1 and 2). After six cycles of therapy, a CT scan showed no evidence of disease and the patient was given a one month break from gemcitabine (erlotinib was continued) to allow for repair of a large ventral hernia. The patient completed 12 cycles of combination therapy at which point a PET/CT showed a continued complete response of all FDG-avid disease; the CA 19-9 remained at a very low level (Figures 1 and 2).

Given the complete response of the patient's disease to treatment and his desire to take a break from intravenous treatments, further chemotherapy was stopped and he continued single-agent erlotinib. During the six months of maintenance erlotinb, his performance status and quality of life were excellent. The CA 19-9 has slowly increased, though still within the normal range. A followup PET/CT after six months of erlotinib showed a localized area of FDG-activity in the portacaval region SUV 9.4, without a clear lymph node or mass seen; all other areas, including the liver, remain without evidence of disease recurrence.

Regarding treatment tolerance, the only grade 3 toxicity (National Cancer Institute Common Terminology Criteria, version 3.0) has been an EGFR-related skin rash on the face, chest and back that has responded well to oral doxycycline and topical clindamycin cream. Minor toxicities have included grade 1 fatigue, grade 2 diarrhea, grade 2 neutropenia and grade 2 anemia.

\section{EGFR testing}

For EGFR mutation analysis, tumor areas of interest were identified, microdissected, and collected cells lysed. After genomic DNA was purified, DNA yield was determined 


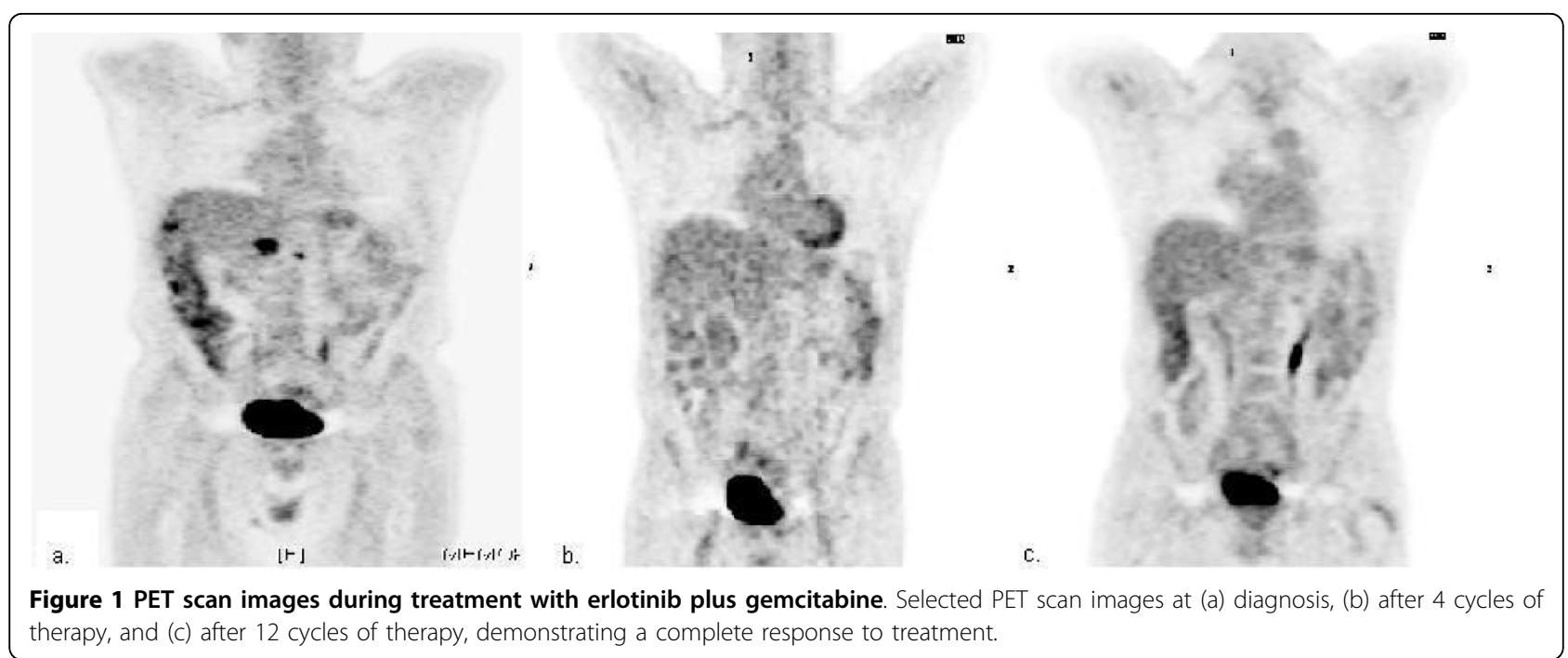

and the sample brought to optimal concentration. Realtime PCR was then used to evaluate for specific mutations, deletions and insertions in the tyrosine kinase domain of the EGFR gene. Eight reactions containing 30 primer and probe sets were used to target specific regions of exons $18-21$ as well as the wild-type sequence. EGFR-mutation analysis by real-time PCR for the 29 known mutations, deletions and insertions found in exons 18-21 of the EGFR tyrosine kinase domain revealed only the wild-type sequence (performed by Clarient Diagnostic Services) (Figure 3).

Assessment of EGFR gene amplification was performed by fluorescence in situ hybridization (FISH) testing of the tumor specimen using the EGFR-CEP (chromosome 7

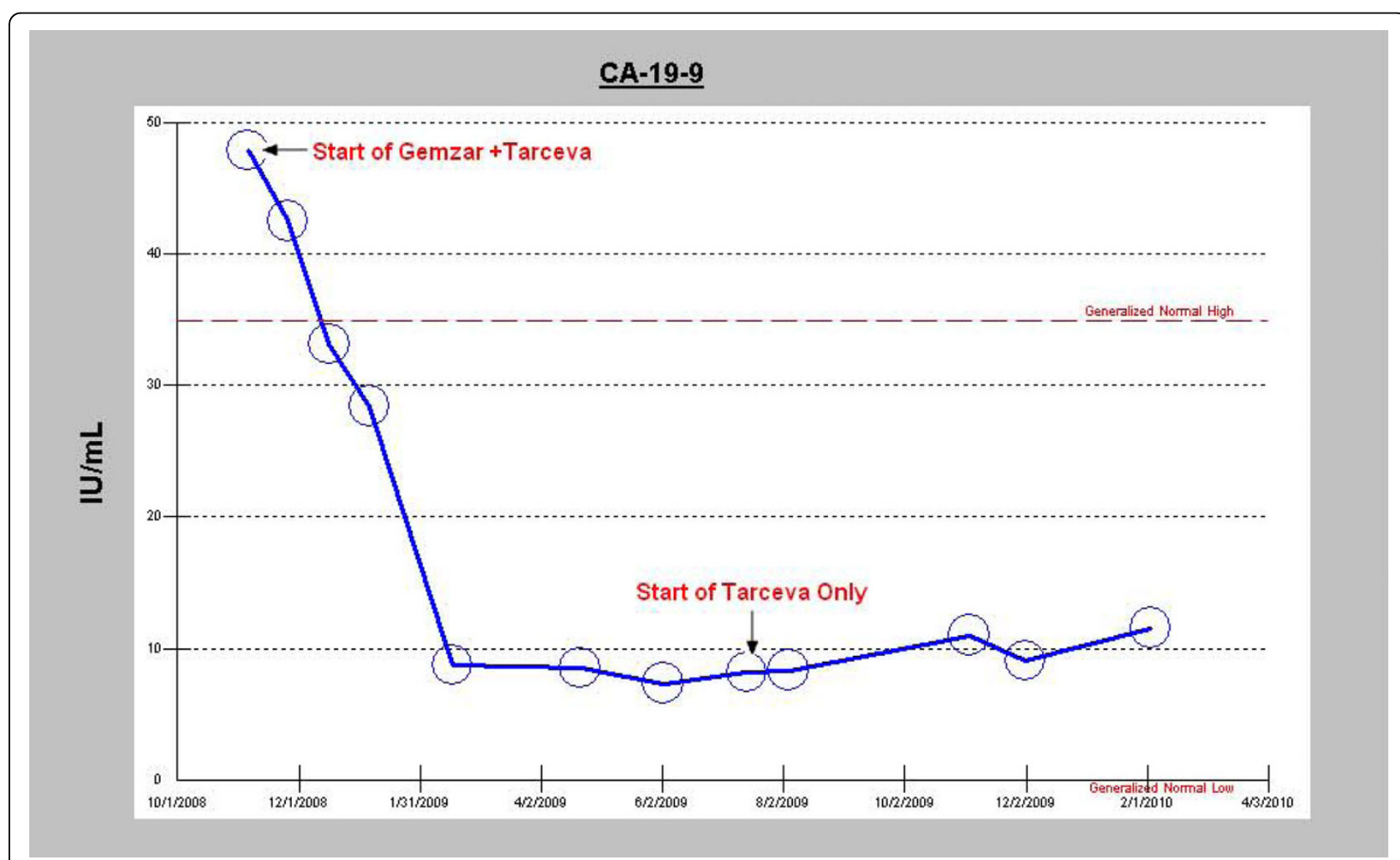

Figure 2 CA 19-9 levels during treatment. Graphical depiction of the decline in CA 19-9 tumor marker levels during treatment with erlotinib plus gemcitabine and with maintenance erlotinib. 


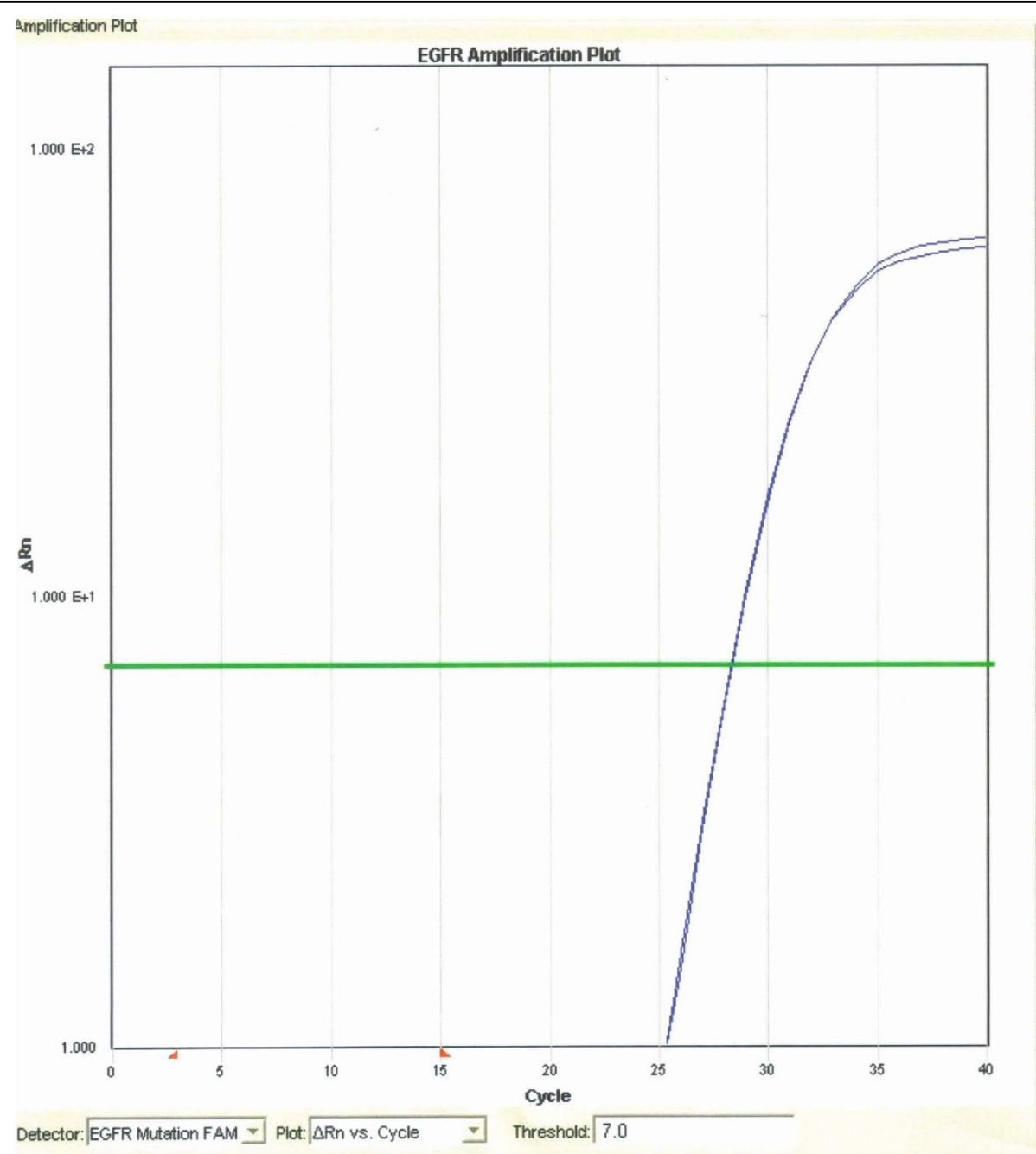

Figure 3 EGFR mutation analysis. Polymerase chain reaction amplification plot of exons 18-21 demonstrating the presence of only wild-type EGFR DNA in the patient's tumor sample. (Performed by Clarient Diagnostic Services, Aliso Viejo, CA).

centromere) dual color DNA probe (performed by Genzyme Genetics). This demonstrated that the EGFR gene was not amplified (Figure 4).

\section{Conclusion}

In a recently published landmark phase III trial of cisplatin plus gemcitabine versus gemcitabine alone for the treatment of BTC, no complete responses were seen among 117 gallbladder cancer patients treated [3]. Similarly, in phase II trials of single-agent gemcitabine given to gallbladder [13] and BTC patients [12], no complete responses were observed. In a recent phase II study in BTC of gemcitabine and oxaliplatin plus the angiogenesis-inhibitor bevacizumab, among 35 patients treated there were no complete responses observed by either PET or CT scans, despite an overall response rate of $40 \%[14]$.
We took a novel approach to the treatment of our patient with stage IV gallbladder cancer and observed a rarely encountered complete response by both PET/CT and dedicated CT scans. Both the response to erlotinib plus chemotherapy and the prolonged disease control observed with single-agent maintenance erlotinib lead us to conclude that erlotinib plus chemotherapy may be an effective treatment for patients with advanced gallbladder cancer. We can not rule out that the observed response was due solely to treatment with gemcitabine. Yet, our unpublished observations of patients with refractory gallbladder cancer who responded to erlotinib plus chemotherapy and the rarity of complete responses to chemotherapy reported in the literature make this seem unlikely.

The tailored use of EGFR-TKI therapy has been pioneered in the area of lung cancer [15]. Patients with 


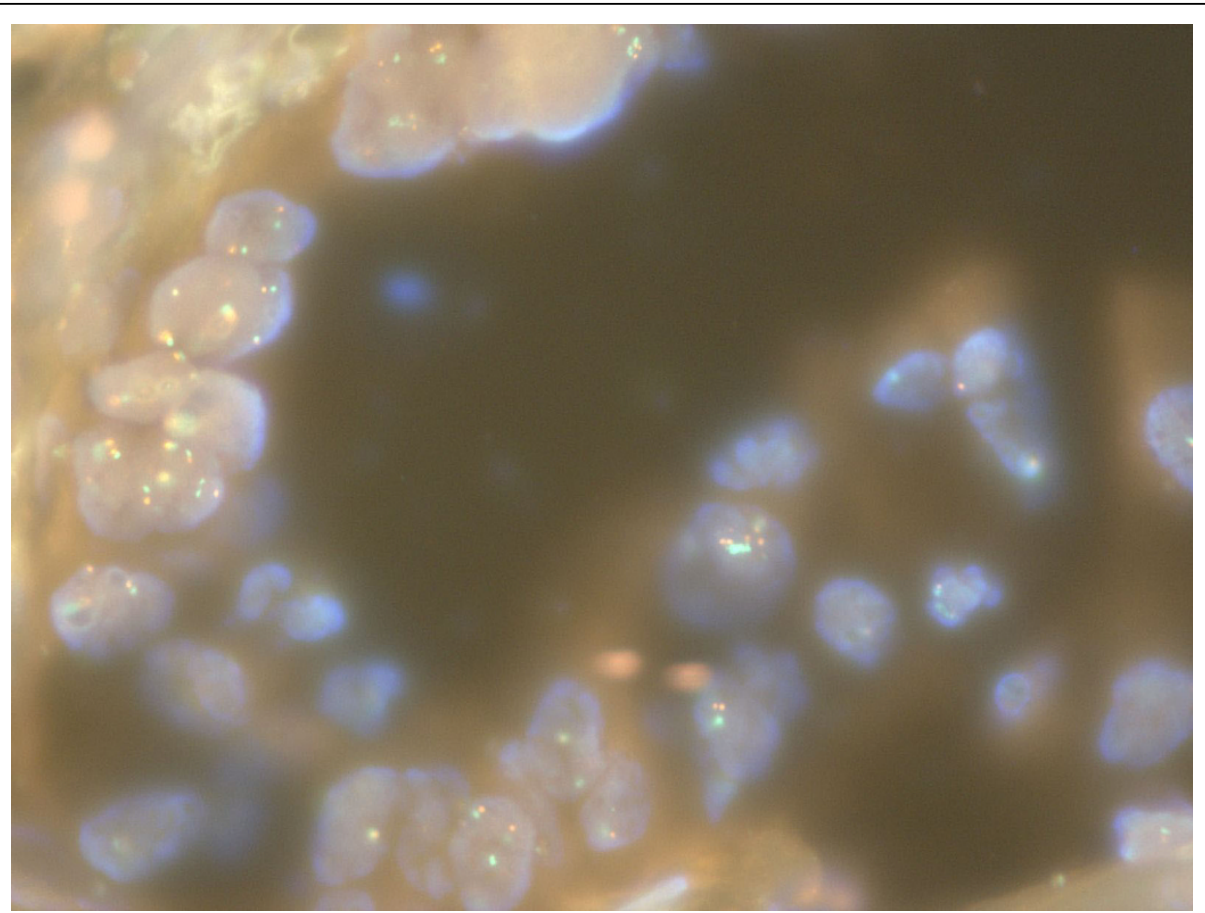

Figure 4 FISH testing for EGFR amplification. Fluorescence in-situ hybridization (FISH) testing of the tumor sample using an EGFR-CEP dual color DNA probe (Vysis) demonstrating lack of EGFR gene amplification.

non-small cell lung cancer whose tumors harbor an EGFR mutation have a superior response to TKI therapy compared with chemotherapy alone [16]. In BTC, a 13$15 \%$ tyrosine kinase domain mutation rate has been reported and it has been suggested that patients with tumor associated EGFR mutations be preferentially enrolled in clinical trials of EGFR-TKIs $[17,18]$.

The patient with gallbladder cancer presented in this report had a rarely encountered compete response in the absence of a tumor associated EGFR mutation. This would suggest that future studies of EGFR-TKI therapy plus chemotherapy in patients with BTCs should not be restricted to those with EGFR mutations. Since gallbladder cancer and cholangiocarcinoma are distinct clinicopathologic entities (despite being grouped together in most clinical trials), it is possible that erlotinib plus chemotherapy may be more efficacious for patients with gallbladder cancer than those with cholangiocarcinoma. Such hypotheses can only be tested in well-designed clinical trials.

\section{Consent}

Written informed consent was obtained from the patient for publication of this case report and any accompanying images. A copy of the written consent is available for review by the Editor-in-Chief of this journal.

\section{Abbreviations}

Abbreviations have been defined within the manuscript.

\section{Acknowledgements}

None. Source of funding: N/A

\section{Author details}

'Department of Medicine, Norwalk Hospital, 34 Maple Street, Norwalk, CT 06856 USA. ${ }^{2}$ Department of Radiology, Norwalk Hospital, 34 Maple Street, Norwalk, CT 06856 USA. ${ }^{3}$ Department of Surgery, Norwalk Hospital, 34 Maple Street, Norwalk, CT 06856 USA.

\section{Authors' contributions}

KM drafted the manuscript; aided in acquisition of all data to be included, ES aided in acquisition and interpretation of the data, RL aided in acquisition of the data, RCF made substantial contributions to the conception, acquisition and analysis of the data and editing of this manuscript. All authors have read and approved the final manuscript.

\section{Authors' Information}

KM: Hospitalist, Norwalk Hospital

ES: Radiologist and Radiology Residency Program Director, Norwalk Hospital RL: Surgeon, Norwalk Hospital

RCF: Oncologist and Director of Research, Whittingham Cancer Center, Norwalk Hospital

\section{Competing interests}

The authors declare that they have no competing interests.

Received: 18 June 2010 Accepted: 20 October 2010

Published: 20 October 2010

\section{References}

1. Xiu AX, Hong TS, Hezel AF, Kooby DA: Current management of gallbladder carcinoma. The Oncologist 2010, 15:168-181.

2. Gallardo J, Rubio B, Villanueva L, Barajas O: Gallbladder cancer, a different disease that needs individual trials. J Clin Oncol 2005, 23:7753-7754.

3. Valle JW, Wasan $\mathrm{H}$, Palmer $\mathrm{DH}$, et al: Cisplatin plus gemcitabine versus gemcitabine for biliary tract cancer. N Engl J Med 2010, 362:1273-1281. 
4. Cunningham D, Humblet $Y$, Siena S, Khayat D, Bleiberg H, Santoro A, Bets D, Mueser M, Harstrick A, Verslype C, Chau I, Van Cutsem E: Cetuximab monotherapy and cetuximab plus irinotecan in irinotecan-refractory metastatic colorectal cancer. N Engl J Med 2004, 351:337-345.

5. Van Cutsem E, Kang Y, Chung H, Shen L, Sawaki A, Lordick F, Hill J, Lehle M, Feyereislova A, Bang Y: Efficacy results from the ToGA trial: A phase III study of trastuzumab added to standard chemotherapy in firstline human epidermal growth factor receptor 2 [HER2]-positive advanced gastric cancer [abstract]. J Clin Oncol 2009, 27:18s.

6. Moore MJ, Goldstein D, Hamm J, Figer A, Hecht JR, Gallinger S, Au HJ, Murawa P, Walde D, Wolff RA, Campos D, Lim R, Din K, Clark G, VoskoglouNomikos T, Ptasynski M, Parulekar W: Erlotinib plus gemcitabine compared with gemcitabine alone in patients with advanced pancreatic cancer: a phase III trial of the National Cancer Institute of Canada Clinical Trials Group. J Clin Oncol 2007, 25:1960-1966.

7. Philip AP, Mahoney MR, Allmer C, Thomas J, Pitot HC, Kim G, Donehower RC, Fitch T, Picus J, Erlichman C: Phase II study of erlotinib in patients with advanced biliary cancer. J Clin Oncol 2006, 24:3069-3074.

8. Sprinzl MF, Schimanski CC, Moehler M, Schadmand-Fischer S, Galle PR, Kanzler S: Gemcitabine in combination with EGF-Receptor antibody (cetuximab) as a treatment of cholangiocarcioma: a case report. BMC Cancer 2006, 6:190.

9. Malka D, Trarbach T, Faroux L, Mendiboure J, de la Fouchardiere C, Viret F, Assenat E, Boucher E, Rosmorduc O, Greten T: A multicenter, randomized phase II trial of gemcitabine and oxaliplatin [GEMOX] alone or in combination with biweekly cetuximab in the first-line treatment of advanced biliary cancer: Interim analysis of the BINGO trial [abstract]. $J$ Clin Oncol 2009, 27:15s.

10. Frank RC: Fighting Cancer with Knowledge and Hope New Haven: Yale University Press 2009, 39-42.

11. Ciardiello F, Giampaolo T: EGFR antagonists in cancer treatment. N Eng/ J Med 2008, 358:1160-1174.

12. Gelibter A, Malaguti $P$, Di Cosimo $S$, Bria E, Ruggeri EM, Carlini $P$, Carboni F, Ettorre GM, Pellicciotta M, Giannarelli D, Terzoli E, Cognetti F, Milella M: Fixed dose-rate gemcitabine infusion as first-line treatment for advanced-stage carcinoma of the pancreas and biliary tree. Cancer 2005, 104:1237-1245.

13. Gallardo JO, Rubio B, Fodor M, Orlandi L, Yanez M, Gamargo C, Ahumada M: A phase II study of gemcitabine in gallbladder carcinoma. Ann Oncol 2001, 12:1403-1406.

14. Zhu AX, Meyerhardt JA, Blaszkowsy LS, Kambadakone AR, Muzikansky A, Zheng H, Clark JW, Abrams TA, Chan JA, Enzinger PC, Bhargava P, Kwak EL, Allen JN, Jain SR, Stuart K, Horgan K, Sheehan S, Fuchs CS, Ryan DP, Sahani DV: Efficacy and safety of gemcitabine, oxaliplatin, and bevacizumab in advanced biliary-tract cancer and correlation of changes in 18-fluorodeoxyglucose PET with clinical outcome: a phase 2 study. Lancet Oncol 2010, 11:48-54.

15. Lynch TJ, Bell DW, Sordella R, Gurubhagavatula S, Okimoto RA, Brannigan BW, Harris PL, Haserlat SM, Supko JG, Haluska FG, Louis DN, Christiani DC, Settleman J, Haber DA: Activating mutations in the epidermal growth factor receptor underlying responsiveness of nonsmall-cell lung cancer to gefitinib. N Engl J Med 2004, 350:2129-2139.

16. Mok TS, Wu Y-L, Thongprasert S, Yang C-H, Chu D-T, Saijo N, Sunpaweravong $P$, Han B, Margono B, Ichinose $Y$, Nishiwaki $Y$, Ohe $Y$, Yang J-J, Chewaskulyong B, Jiang H, Duffield EL, Watkins CL, Armour AA, Fukuoka M: Gefitinib or carboplatin-paclitaxel in pulmonary adenocarcinoma. N Engl J Med 2009, 361:947-957.

17. Gwak G-Y, Yoon J-H, Shin CM, Ahn YJ, Chung JK, Kim YA, Kim TY, Lee H-S: Detection of response-predicting mutations in the kinase domain of the epidermal growth factor receptor gene in cholangiocarcinoma. J Cancer Res Clin Oncol 2005, 131:649-62.

18. Leone F, Cavalloni G, Pignochino Y, Sarotto I, Ferraris R, Piacibello W, Venesio T, Capussotti L, Risio M, Aglietta M: Somatic mutations of epidermal growth factor receptor in bile duct and gallbladder carcinoma. Clin Cancer Res 2006, 12:1680-1685.

\section{Pre-publication history}

The pre-publication history for this paper can be accessed here: http://www.biomedcentral.com/1471-2407/10/570/prepub

doi:10.1186/1471-2407-10-570

Cite this article as: Mody et al:: Complete response in gallbladder cancer to erlotinib plus gemcitabine does not require mutation of the epidermal growth factor receptor gene: a case report. BMC Cancer 2010 10:570

\section{Submit your next manuscript to BioMed Central and take full advantage of:}

- Convenient online submission

- Thorough peer review

- No space constraints or color figure charges

- Immediate publication on acceptance

- Inclusion in PubMed, CAS, Scopus and Google Scholar

- Research which is freely available for redistribution

Submit your manuscript at www.biomedcentral.com/submit
Biomed Central 